\title{
Cardiovascular Risk Prediction, Glycemic Control, and Determinants in Diabetic and Hypertensive Patients in Massawa Hospital, Eritrea: Cross-Sectional Study on 600 Subjects
}

\author{
Berhe Tesfai $\mathbb{D}^{\prime}$ \\ Fitsum Kibreab (D) ${ }^{2}$ \\ Abraham Dawit' \\ Zemui Mekonen' \\ Solomon Ghebrezghi ${ }^{1}$ \\ Senait Kefele' \\ 'Medical Department, Massawa Hospital, \\ Northern Red Sea Zone, Ministry of \\ Health, Massawa, Eritrea; ${ }^{2} \mathrm{Health}$ \\ Research and Resources Center \\ Divisiony, Ministry of Health, Asmara, \\ Eritrea
}

Background: Hypertension and diabetes are key determinants of cardiovascular risks. The objective of this study was to calculate 10-year incidence of cardiovascular risk, determine cardiovascular risk factors, and evaluate how diabetes and hypertension are controlled in patients in Massawa Hospital, Eritrea.

Methods: This was a hospital-based cross-sectional study using census sampling. A checklist and interview were used as data-collection tool from October 10 to November 20, 2020. Written consent was obtained from each study participant before starting the study. Descriptive statistics were wasused, and results are presented in percentages in tables, $p<0.05$ was considered significant.

Results: A total of 600 patients were enrolled in the study, dominated by the Tigrigna $(58.7 \%)$ and Tigre $(26.7 \%)$ ethnic groups. About half the patients $(58.8 \%)$ had a body-mass index of $18-25 \mathrm{~kg} / \mathrm{m}^{2}$, with abdominal circumference of $<95 \mathrm{~cm}(74 \%)$. Most $(93.5 \%)$ patients had $<10 \%$ risk of cardiovascular complications in the coming 10 years. Age showed significant association with hypertension, diabetes mellitus, cardiovascular risk, and poor glycemic and blood-pressure control $(p<0.001)$. Body-mass index, abdominal obesity, and history of stroke were associated with hypertension and diabetes mellitus $(p<0.001)$. Moreover, smoking, hypertension, and monthly income were associated with higher cardiovascular risk $(p<0.001)$. In addition, hypertension and abdominal obesity were associated with glycemic control $(p<0.001)$, and blood-pressure control was significantly associated with diabetes and hypertension $(p<0.001)$.

Conclusion: Age and hypertension were associated with diabetes, cardiovascular risk and poor glycemic control, and smoking, abdominal obesity, and monthly income also significant associations with higher cardiovascular risk and glycemic control. Cessation and adjustment of modifiable factors, such as smoking, hypertension, and regular exercise are highly recommended.

Keywords: cardiovascular, glycemic control, diabetes, hypertension, Massawa Hospital

\section{Introduction}

The 2016 World Health Organization (WHO) global report of diabetes mellitus (DM) estimated worldwide adult diabetes prevalence of 422 million individuals in 2014, rising from $4.7 \%$ in 1980 to $8.5 \%$ in 2014, with the greatest increment in middle- and low-income countries. ${ }^{1}$ This number will probably overcome the
Correspondence: Berhe Tesfai Medical Department, Massawa Hospital, Northern Red Sea Zone, Ministry of Health, Massawa, Eritrea

Email berhetesfai04@gmail.com 
previous WHO projection of 439 million adults with diabetes for 2030. Currently, 1.5 million deaths are directly attributed to DM each year. ${ }^{2}$

According to the International Diabetes Federation, in 2015 DM led to 5 million deaths worldwide, which translated to one death in every 6 seconds, and approximately $70 \%$ of DM-related deaths were attributed to cardiovascular disease (CVD). The development of DM-related complications significantly increases medical costs. ${ }^{3}$

American and Canadian diabetes associations' guidelines both include 10-year overall CVD-risk stratification to identify high-risk patients for more intensive medical and psychosocial interventions. ${ }^{3}$ The classical risk factors for the development of CVD in subjects with DM are poor glycemic control, obesity, dyslipidemia, and hypertension. ${ }^{4}$ Successful management of CVD associated with DM represents a major challenge for clinicians. An effective way of tackling this problem is to detect the associated risk factors and to target treatment toward their improvement. ${ }^{5}$

Risk assessment must take into account the major risk factors (cigarette smoking, elevated blood pressure, abnormal serum lipids, and hyperglycemia) and predisposing risk factors (excess body weight, abdominal obesity, physical inactivity, and family history of CVD). Identification of risk factors is a major first step to develop a plan for risk reduction in persons with $\mathrm{DM}^{6}$ Although CVD accompanying DM is on the rise, many unanswered questions remain concerning the temporal relationships between DM and CVD, contributions of conventional risk factors, and the role of DM-specific risk factors. ${ }^{7}$

Risk stratification is widely used in the prognostic assessment of patients with a variety of clinical disorders on the unquestioned assumption that the intensity of treatment should be proportionate to the risk of an adverse event during some finite period. ${ }^{8}$ Recent guidelines for CVD management in DM are based on the premise that most patients with DM are at high risk of future CVD events. When DM exists in patients with established CVD, absolute risk of future events is very high. ${ }^{9}$

Risk stratification is necessary to individualize treatment. Lifetime risk seems to be invariably high in almost all patients with DM. Age $>40$ years, DM duration $>10$ years, presence of a first-degree family history of premature CVD, male sex, high blood pressure, low-density lipoprotein cholesterol $>100 \mathrm{mg} / \mathrm{dL}$, low renal function, microalbuminuria, presence of nonalcoholic fatty-liver disease, obstructive sleep apnea, erectile dysfunction, and especially metabolic syndrome, chronic hyperglycemia, and severe hypoglycemia are conditions that increase $\mathrm{CV}$ risk (CVR). ${ }^{2}$

As clearly outlined in the 2016 European guidelines on CVD prevention in clinical practice, individuals with DM and CVD, DM with target-organ damage, DM with three or more major risk factors, DM duration of $>20$ years, or T1DM at the age of 40 years with early onset are at very high risk (10-year risk of CVD death $>10 \%) .{ }^{10}$

As with many developing countries, Eritrea is facing the burden of non-communicable diseases (NCDs) as a result of current epidemiological and nutritional transitions. ${ }^{11,12}$ According to National Health Information System of Eritrea, DM is one of the leading causes of morbidity and mortality, mainly in adults: 78,686 new cases and 926 deaths from DM were reported from hospitals and health centers in the years 1998-2012. ${ }^{13}$ Moreover, 695 amputations due to DM were also reported between 2006-2012, indicating that it is not only a leading cause of morbidity but also a cause of disability. ${ }^{14}$ In Eritrea, research on solving this problem has not been done before, and thus this research will fill this gap and can be used as a baseline for further and larger national studies and to institute appropriate interventions in preventing CV-related mortality and morbidity in these groups of patients.

The objective of this study was to calculate and predict 10-year incidence of CVR in patients with hypertension and DM based on the WHO prediction charts and to determine the CVR factors that significantly predict their CVD. It also evaluated how DM and hypertension are controlled in these patients and examine the association of CVR with predisposing factors.

\section{Methods}

\section{Study Design, Setting, and Population}

This was a hospital-based, crosssectional study using census sampling of patients with DM and hypertension on follow-up at Massawa Hospital's NCD clinic.

The Northern Red Sea zone has a population of 491,657 and ten subzones, with Tigre, Tigrigna, Rashaida, Afar, and Saho ethnic composition. The city of Massawa has 32,860 inhabitants, and Massawa Hospital has an NCD clinic that serves patients from Massawa, Foro, Ghelaelo, and Dahlak subzones. ${ }^{15}$ Since 2010, a total of 1,050 patients with DM and 870 patients with hypertension had registered at the NCD clinic for 
treatment and follow-up. In 2020, 820 of patients with DM and 701 with hypertension were having regular follow-up, and the rest were lost tom follow-up, died, or were transferred to other hospitals. ${ }^{15}$

\section{Data Collection}

A checklist was used to obtain sociodemographic information of patients, eg, age, sex, and ethnicity, and then a semistructured questionnaire and interview was used to collect specific patient details. History of alcohol intake, smoking status, sedentary life-style and DM duration were recorded, and weight, height, and body-mass index (BMI) measured for all patients with DM and hypertension. Mean blood pressure (average of last three visits) and mean fasting blood sugar (FBS; average of last three visits for patients with DM only) were also calculated. Data were collected from October 10 to November 20, 2020 (6 weeks).

\section{Inclusion and Exclusion Criteria}

All patients with DM and hypertension with complete clinical records and duration of illness, regardless of residence or age, and on regular follow-up at Massawa Hospital's NCD clinic were included. Patients lost to follow-up during the study period and who had incomplete medical records, communication disabilities, or mental disorders were excluded from the research.

\section{Definition of Variables}

Abdominal obesity was defined as waist circumference $\geq 100 \mathrm{~cm}$. Weight was measured on portable digital scales and height using a vertical stadiometer. BMI was calculated as weight $(\mathrm{kg}) /$ height per $\mathrm{m}^{2}$. Underweight, normal, overweight, and obese were defined as $<18 \mathrm{~kg} / \mathrm{m}^{2}, 18$ $25 \mathrm{~kg} / \mathrm{m}^{2}, 26-30 \mathrm{~kg} / \mathrm{m}^{2}$, and $>30 \mathrm{~kg} / \mathrm{m}^{2}$, respectively. Patients who smoked at least one cigarette per day were considered smokers. Mean FBS of $75-150 \mathrm{mg} / \mathrm{dL}$ was considered well controlled and $>150 \mathrm{mg} / \mathrm{dL}$ poorly controlled, and mean blood pressure was grouped into $<130$ / $80 \mathrm{mmHg}$ (well controlledhypertension) and >130/80 $\mathrm{mmHg}$ (poorly controlled hypertension).

WHO charts to predict CVR in patients with DM and hypertension were used. These include age, sex, systolic blood pressure, DM, smoking, and cholesterol level. Because of the unavailability of a lipid panel in our hospital, we used the charts for countries that cannot determine cholesterol levels (ie, no cholesterol level) with the other variables. All participants were divided into four groups for CVR prediction: low risk $(<10 \%)$, medium risk $(10 \%-$ $20 \%)$, moderate risk $(20 \%-30 \%)$, and high risk $(>30 \%)$.

\section{Data Management and Analysis}

Data were entered into CSPro 7.3 and analyzed with SPSS 20. Results are presented as percentages and frequencies and in tables. Descriptive statistics were used to calculate the incidence of total CVD, and distribution of risk factors was cross-tabulated by complication. Associations between risk factors with $\mathrm{DM}$ and hypertension were assessed. Further associations were calculated among the variables, glycemic control, and blood-pressure control. In this study, $p<0.05$ was considered significant.

\section{Ethics}

Ethics approval was obtained from the Ministry of Health Research and Ethical Clearance Committee on January 21, 2020, and zonal and hospital medical offices were informed. Confidentiality of patients' medical records was kept secure. Patients provided written consent, were informed about the purpose of the study, and that it was conducted in accordance with the Declaration of Helsinki. Patients were also informed that they had the right to withdraw at any stage of the study and to skip questions if they wished.

\section{Results}

\section{Background of Participants}

A total of 600 patients were enrolled, almost all from Massawa (98\%) and dominated by the Tigrigna (58.7\%) and Tigre (26.7\%) ethnic groups. Only $8 \%$ and $9.3 \%$ of the patients were smokers and alcohol consumers, respectively. In sum, 404 and 194 patients had DM only and hypertension only, respectively, and 141 had both DM and hypertension. A quarter of the patients $(24.7 \%)$ reported vision problems, and $2.8 \%$ and $0.8 \%$ had a history of stroke and amputation, respectively. (Table 1)

\section{Medical Profile of Participants}

Most $(93.5 \%)$ of the patients were aged $>40$ years, and about half (58.8\%) had a BMI of $18-25 \mathrm{~kg} / \mathrm{m}^{2}$ and abdominal circumference $<95 \mathrm{~cm}$ (74\%). Half (49\%) had a monthly income $>$ ERN1,000 and $50.3 \%$ usually walked $<1 \mathrm{~km}$ from home to work, regularly on foot (31.5\%). A tenth (11.2\%) had a history of chronic illnesses other than DM and hypertension. A majority had type $2 \mathrm{DM}$ and were taking metformin and glibenclamide as treatment. 
Table I Background of study participants $(n=600)$

\begin{tabular}{|l|l|l|l|}
\hline & Responses & $\mathbf{n}$ & $\%$ \\
\hline Zone & NRS & 599 & 99.8 \\
& Debub & $\mathrm{I}$ & 0.2 \\
\hline Subzone & Massawa & 588 & 98.0 \\
& Foro & 5 & 0.8 \\
& Shieb & 4 & 0.7 \\
& Others & 3 & 0.6 \\
\hline \multirow{2}{*}{ thnicity } & Tigrigna & 352 & 58.7 \\
& Tigre & 160 & 26.7 \\
& Saho & 38 & 6.3 \\
& Afar & 39 & 6.5 \\
& Others & 11 & 1.8 \\
\hline Smoking & Yes & 48 & 8.0 \\
& No & 552 & 92.0 \\
\hline Alcohol & Yes & 55 & 9.3 \\
& No & 544 & 90.7 \\
\hline Diabetes mellitus & Yes & 405 & 67.7 \\
& No & 194 & 32.3 \\
\hline Hypertension & Yes & 337 & 56.2 \\
& No & 263 & 43.8 \\
\hline Vision problem & Yes & 148 & 24.7 \\
& No & 452 & 75.3 \\
\hline History of amputation & Yes & 17 & 2.8 \\
& No & 583 & 97.2 \\
\hline & No & 5 & 0.8 \\
& & 595 & 99.2 \\
\hline & 600 & 100 \\
\hline
\end{tabular}

About half had had DM for $1-5$ years (46.3\%), 58.5\% had hypertension, and more than half $(57.4 \%)$ had a mean FBS of $75-150 \mathrm{mg} / \mathrm{dL}$. Moreover, $93.5 \%$ of the patients had $<10 \%$ risk of CVD complications, and $5.3 \%$ and $0.7 \%$ had $10 \%-20 \%$ and $30 \%-40 \%$ risk of CVD complications in the coming 10 years respectively. (Table 2)

\section{Associations of Medical Profiles with DM and Hypertension}

All patients aged $<21$ years had DM only, and the greatest number of those with DM were aged 41-60 years $(p<0.001)$. A tenth had hypertension (10.2\%) and DM $(8.4 \%)$ were smokers. Hypertension was common in those with BMI $<18 \mathrm{~kg} / \mathrm{m}^{2}(46 \%, p<0.001)$, and DM was significantly associated with $\mathrm{BMI}>30 \mathrm{~kg} / \mathrm{m}^{2}(78.5 \%$, $p<0.003)$. Hypertension and DM were common in these with abdominal circumference $<95 \mathrm{~cm}$ and $>100 \mathrm{~cm}$, respectively $(p<0.001)$. Age, DM, hypertension, BMI, abdominal obesity, and history of stroke were significantly associated with history of hypertension and DM. (Table 3)

\section{Associations of Patient Background with CVR}

Overall, $6.5 \%$ of patients had a CVR $>10 \%$ in the coming 10 years. Patients aged $>61$ years and males had higher CVR than their counterparts. All patients with CVR $<10 \%$ were from Massawa, and risk was higher in the Saho ethnic group. CVR was higher in smokers $(p<0.001)$ and alcohol consumers than their counterparts. Hypertensive patients had higher CVR $(p=0.007)$. Patients on a monthly income $>$ ERN2,000 had higher CVR than with those on lower monthly income $(p=0.007)$. Those with a history of vision problems and stroke had higher CVR than their counterparts (Table 4).

\section{Associations of Medical Profiles with Mean FBS and Blood Pressure}

A majority (58.4\%) of patients with DM and $77.8 \%$ of all patients had mean FBS of 75-150 mg/dL and mean blood pressure of $<130 / 80 \mathrm{mmHg}$, respectively. Older patients with DM had well controlled DM when compared with the other age-groups $(p<0.001)$. Three from Foro had poorly controlled DM, and a majority of these were Saho. Patients with DM and hypertension had well-controlled FBS compared to those with DM only $(\mathrm{I}<0.001)$, and hypertensive patients with DM had well-controlled blood pressure compared to those with hypertension only $(p<0.001)$. DM patients with abdominal circumference 95-100 $\mathrm{cm}$ had well-controlled DM compared to the other categories $(p<0.001)$. Patients on a monthly income $>$ ERN2,000 and those who walked $<1 \mathrm{~km}$ from home to work had poorly controlled DM compared to their counterparts - 30.8\% and $81 \%$ respectively. BMI, history of stroke, history of amputation, and vision problems did not show significant associations with mean FBS.

Most patients (77.8\%) had controlled blood pressure $<130 / 80 \mathrm{mmHg}$, which was significantly associated with age, DM, and hypertension $(p<0.001)$. Smoking, alcohol intake, BMI, and abdominal obesity did not show significant associations with mean blood pressure (Table 5).

\section{Discussion}

Several predisposing factors simultaneously affect the development of CVD in patients with DM and 
Table 2 Medical profiles of patients

\begin{tabular}{|c|c|c|}
\hline & $\mathbf{n}$ & $\%$ \\
\hline \multicolumn{3}{|l|}{ Age (years) } \\
\hline$<40$ & 39 & 6.5 \\
\hline $40-59$ & 267 & 44.5 \\
\hline$\geq 60$ & 294 & 49.0 \\
\hline \multicolumn{3}{|l|}{ BMI } \\
\hline$<18 \mathrm{~kg} / \mathrm{m}^{2}$ & 50 & 8.3 \\
\hline $18-25 \mathrm{~kg} / \mathrm{m}^{2}$ & 353 & 58.8 \\
\hline $26-30 \mathrm{~kg} / \mathrm{m}^{2}$ & 132 & 22.0 \\
\hline$>30 \mathrm{~kg} / \mathrm{m}^{2}$ & 65 & 10.8 \\
\hline \multicolumn{3}{|c|}{ Abdominal circumference $(\mathrm{cm})$} \\
\hline$<95$ & 444 & 74.0 \\
\hline $95-100$ & 77 & 12.8 \\
\hline$>100$ & 79 & 13.2 \\
\hline \multicolumn{3}{|l|}{ Monthly income (ERN) } \\
\hline$<500$ & 220 & 36.7 \\
\hline $500-1,000$ & 104 & 17.3 \\
\hline $\mathrm{I}, 00 \mathrm{I}-2,000$ & 190 & 31.7 \\
\hline$>2,000$ & 86 & 14.3 \\
\hline \multicolumn{3}{|c|}{ Distance from home to work } \\
\hline$<1 \mathrm{~km}$ & 302 & 50.3 \\
\hline $\mathrm{I}-5 \mathrm{~km}$ & 270 & 45.0 \\
\hline$>5 \mathrm{~km}$ & 28 & 4.7 \\
\hline \multicolumn{3}{|l|}{ Transport to work } \\
\hline Bicycle & 70 & 11.7 \\
\hline Car & 89 & 14.8 \\
\hline On foot & 189 & 31.5 \\
\hline No & 252 & 41.0 \\
\hline \multicolumn{3}{|l|}{ Other chronic illness } \\
\hline Yes & 67 & 11.2 \\
\hline No & 533 & 88.8 \\
\hline \multicolumn{3}{|l|}{ Type of diabetes mellitus } \\
\hline I & 71 & 17.6 \\
\hline II & 334 & 82.4 \\
\hline \multicolumn{3}{|c|}{ Duration of diabetes mellitus } \\
\hline$<1$ year & 20 & 5.0 \\
\hline $\mathrm{I}-5$ years & 187 & 46.3 \\
\hline $6-10$ years & 102 & 25.2 \\
\hline$\geq 1 \mathrm{I}$ years & 95 & 23.5 \\
\hline \multicolumn{3}{|l|}{ Type of DM treatment } \\
\hline Glibenclamide & 116 & 28.7 \\
\hline Metformin and glibenclamide & 171 & 42.3 \\
\hline
\end{tabular}

(Continued)
Table 2 (Continued).

\begin{tabular}{|c|c|c|}
\hline & $\mathbf{n}$ & $\%$ \\
\hline Metformin & 30 & 7.4 \\
\hline Insulin & 87 & 21.5 \\
\hline \multicolumn{3}{|c|}{ Duration of hypertension } \\
\hline$<1$ year & 4 & 1.2 \\
\hline $\mathrm{I}-5$ years & 189 & 58.5 \\
\hline $6-10$ years & 94 & 29.1 \\
\hline$\geq 11$ years & 36 & II.I \\
\hline \multicolumn{3}{|l|}{ Mean FBS } \\
\hline $75-120 \mathrm{mg} / \mathrm{dL}$ & 92 & 22.8 \\
\hline $121-150 \mathrm{mg} / \mathrm{dL}$ & 144 & 35.6 \\
\hline $151-200 \mathrm{mg} / \mathrm{dL}$ & 94 & 23.3 \\
\hline$>200$ & 74 & 18.3 \\
\hline \multicolumn{3}{|c|}{ Mean blood pressure } \\
\hline$<130 / 80 \mathrm{mmHg}$ & 467 & 77.8 \\
\hline$>130 / 80 \mathrm{mmHg}$ & 133 & 22.2 \\
\hline \multicolumn{3}{|c|}{ Cardiovascular risk prediction } \\
\hline$<10 \%$ & 561 & 93.5 \\
\hline $10 \%-20 \%$ & 32 & 5.3 \\
\hline $20 \%-30 \%$ & 3 & 0.5 \\
\hline $30 \%-40 \%$ & 4 & 0.7 \\
\hline Total & 600 & 100 \\
\hline
\end{tabular}

hypertension. Modification of lifestyle habits is at the heart of the public-health strategy for prevention of CVD. The objective of this study was to identify CVR and predictors for the increased CVR of patients with DM and hypertension.

This research revealed that $93.5 \%$ of patients with DM and hypertension had $<10 \%$ CVD risk in the coming 10 years and $5.3 \%, 0.5 \%$, and $0.7 \%$ CVD risk of $10 \%-20 \%$, $20 \%-30 \%$, and $\geq 30 \%$ respectively. This was lower than other research, where $78.4 \%$ of subjects had CVD risk of $<10 \%$ and for the risk categories of $10 \%-20 \%, 20 \%-30 \%$, and $>30 \%$, CVD risk was $7 \%, 2 \%$, and $1.9 \%$ respectively. ${ }^{16}$ Another study showed similar results: $74 \%$ showed low CVD risk, $14 \%$ medium risk, and $12 \%$ high risk. ${ }^{17}$ This result showed that most patients with DM and hypertension in Massawa Hospital were at low risk of CVD incidence in the coming 10 years, but those who are should be identified and interventions institutionalized to lower the risk by modifying risk factors. 
Table 3 Association of patients' medical profiles with DM and hypertension $(n=600)$

\begin{tabular}{|c|c|c|c|c|c|c|}
\hline & \multicolumn{2}{|c|}{ Diabetes mellitus } & \multirow[t]{2}{*}{$p$} & \multicolumn{2}{|c|}{ Hypertension } & \multirow[t]{2}{*}{$p$} \\
\hline & No, n (\%) & Yes, n (\%) & & No, n (\%) & Yes, n (\%) & \\
\hline \multicolumn{7}{|c|}{ Age (years) } \\
\hline $\begin{array}{l}<2 I \\
2 I-40 \\
4 I-60 \\
\geq 6 I\end{array}$ & $\begin{array}{l}0 \\
13(25.5) \\
83(26.3) \\
100(44.1)\end{array}$ & $\begin{array}{l}6(100) \\
38(74.5) \\
233(73.7) \\
127(55.9)\end{array}$ & $<0.001$ & $\begin{array}{l}6(100) \\
37(72.5) \\
177(56.0) \\
57(25.1)\end{array}$ & $\begin{array}{l}0 \\
14(27.5) \\
139(44.0) \\
170(74.9)\end{array}$ & $<0.001$ \\
\hline \multicolumn{7}{|l|}{ Sex } \\
\hline $\begin{array}{l}\text { Female } \\
\text { Male }\end{array}$ & $\begin{array}{l}86(35.4) \\
110(30.8)\end{array}$ & $\begin{array}{l}157(64.6) \\
247(69.2)\end{array}$ & 0.240 & $\begin{array}{l}\text { II4(46.9) } \\
163(45.7)\end{array}$ & $\begin{array}{l}129(53.1) \\
194(54.3)\end{array}$ & 0.762 \\
\hline \multicolumn{7}{|c|}{ Subzone } \\
\hline $\begin{array}{l}\text { Massawa } \\
\text { Foro } \\
\text { Shieb } \\
\text { Others }\end{array}$ & $\begin{array}{l}194(33.0) \\
2(40.0) \\
0 \\
0\end{array}$ & $\begin{array}{l}394(67.0) \\
3(60.0) \\
4(100) \\
3(100)\end{array}$ & 0.616 & $\begin{array}{l}268(45.6) \\
2(40.0) \\
4(100) \\
3(100)\end{array}$ & $\begin{array}{l}320(54.4) \\
3(60.0) \\
0 \\
0\end{array}$ & 0.139 \\
\hline \multicolumn{7}{|c|}{ Ethnicity } \\
\hline $\begin{array}{l}\text { Afar } \\
\text { Tigrigna } \\
\text { Saho } \\
\text { Tigre } \\
\text { Others }\end{array}$ & $\begin{array}{l}I 8(46.2) \\
I I 2(3 I .8) \\
I I(28.9) \\
54(33.8) \\
I(9.1)\end{array}$ & $\begin{array}{l}21(53.8) \\
240(68.2) \\
27(71.1) \\
106(66.3) \\
10(90.9)\end{array}$ & 0.435 & $\begin{array}{l}10(25.6) \\
167(47.4) \\
21(55.3) \\
70(43.8) \\
9(81.8)\end{array}$ & $\begin{array}{l}29(74.4) \\
185(52.6) \\
17(44.7) \\
90(56.3) \\
2(18.2)\end{array}$ & 0.26 \\
\hline \multicolumn{7}{|c|}{ Smoking history } \\
\hline $\begin{array}{l}\text { No } \\
\text { Yes }\end{array}$ & $\begin{array}{l}\text { I82(33.0) } \\
\mid 4(29.2)\end{array}$ & $\begin{array}{l}370(67.0) \\
34(70.8)\end{array}$ & 0.590 & $\begin{array}{l}249(45.1) \\
28(58.3)\end{array}$ & $\begin{array}{l}303(54.9) \\
20(4 I .7)\end{array}$ & 0.078 \\
\hline \multicolumn{7}{|c|}{ Alcohol-intake history } \\
\hline $\begin{array}{l}\text { No } \\
\text { Yes }\end{array}$ & $\begin{array}{l}\text { I85(34.0) } \\
\text { II(19.5) }\end{array}$ & $\begin{array}{l}359(66.0) \\
45(80.4)\end{array}$ & 0.29 & $\begin{array}{l}247(45.4) \\
30(53.6)\end{array}$ & $\begin{array}{l}297(54.6) \\
26(46.4)\end{array}$ & 0.243 \\
\hline \multicolumn{7}{|l|}{ DM } \\
\hline $\begin{array}{l}\text { No } \\
\text { Yes }\end{array}$ & $\begin{array}{l}189(97.4) \\
7(1.7)\end{array}$ & $\begin{array}{l}5(2.6) \\
399(98.3)\end{array}$ & $<0.001$ & $\begin{array}{l}4(2.1) \\
273(67.2)\end{array}$ & $\begin{array}{l}190(97.9) \\
133(32.8)\end{array}$ & $<0.001$ \\
\hline \multicolumn{7}{|c|}{ Hypertension } \\
\hline $\begin{array}{l}\text { No } \\
\text { Yes }\end{array}$ & $\begin{array}{l}0 \\
196(58.2)\end{array}$ & $\begin{array}{l}263(100) \\
|4|(4 \mid .8)\end{array}$ & $<0.001$ & $\begin{array}{l}262(99.6) \\
15(4.5)\end{array}$ & $\begin{array}{l}\mathrm{I}(0.4) \\
322(95.5)\end{array}$ & $<0.001$ \\
\hline \multicolumn{7}{|c|}{ BMI $\left(\mathrm{kg} / \mathrm{m}^{2}\right)$} \\
\hline $\begin{array}{l}<18 \\
18-25 \\
26-30 \\
>30\end{array}$ & $\begin{array}{l}23(46.0) \\
127(36.0) \\
32(24.2) \\
14(21.5)\end{array}$ & $\begin{array}{l}27(54.0) \\
226(64.0) \\
100(75.8) \\
51(78.5)\end{array}$ & 0.003 & $\begin{array}{l}23(46.0) \\
149(42.2) \\
69(52.3) \\
36(55.4)\end{array}$ & $\begin{array}{l}27(54.0) \\
204(57.8) \\
63(47.7) \\
29(44.6)\end{array}$ & 0.093 \\
\hline \multicolumn{7}{|c|}{ Abdominal circumference $(\mathrm{cm})$} \\
\hline $\begin{array}{l}<95 \\
95-100 \\
>100\end{array}$ & $\begin{array}{l}168(37.8) \\
10(13.0) \\
18(22.8)\end{array}$ & $\begin{array}{l}276(62.2) \\
61(77.2) \\
61(77.2)\end{array}$ & $<0.001$ & $\begin{array}{l}20 I(45.3) \\
39(50.6) \\
37(46.8)\end{array}$ & $\begin{array}{l}243(54.7) \\
38(49.4) \\
42(53.2)\end{array}$ & 0.677 \\
\hline
\end{tabular}

(Continued) 
Table 3 (Continued).

\begin{tabular}{|c|c|c|c|c|c|c|}
\hline & \multicolumn{2}{|c|}{ Diabetes mellitus } & \multirow[t]{2}{*}{$p$} & \multicolumn{2}{|c|}{ Hypertension } & \multirow[t]{2}{*}{$p$} \\
\hline & No, n (\%) & Yes, n (\%) & & No, n (\%) & Yes, n (\%) & \\
\hline \multicolumn{7}{|c|}{ Monthly income (ERN) } \\
\hline$<500$ & $72(32.7)$ & I48(67.3) & 0.012 & $102(46.4)$ & $118(53.6)$ & 0.768 \\
\hline $500-1,000$ & $47(45.2)$ & $57(54.8)$ & & $44(42.3)$ & $60(57.7)$ & \\
\hline $\mathrm{I}, 00 \mathrm{I}-2,000$ & $56(29.5)$ & $134(70.5)$ & & $88(46.3)$ & $102(53.7)$ & \\
\hline$>2,000$ & $21(24.4)$ & $65(75.6)$ & & $43(50.0)$ & $43(50.0)$ & \\
\hline \multicolumn{7}{|c|}{ Distance from home to work $(\mathrm{km})$} \\
\hline$<1$ & $92(30.5)$ & $210(69.5)$ & 0.509 & 147(48.7) & $155(51.3)$ & 0.461 \\
\hline $\mathrm{I}-5 \mathrm{~km}$ & $94(34.8)$ & $175(65.2)$ & & $118(43.7)$ & $152(56.3)$ & \\
\hline$>5$ & $10(35.7)$ & $18(64.3)$ & & $12(42.9)$ & $15(57.1)$ & \\
\hline \multicolumn{7}{|c|}{ Vision problem } \\
\hline No & $150(33.2)$ & $302(66.8)$ & 0.636 & $210(46.5)$ & $242(53.5)$ & 0.801 \\
\hline Yes & $46(31.1)$ & $102(68.9)$ & & $67(45.3)$ & $8 I(54.7)$ & \\
\hline \multicolumn{7}{|c|}{ History of stroke } \\
\hline No & $186(31.9)$ & $397(68.1)$ & 0.020 & $277(47.5)$ & $306(52.5)$ & $<0.001$ \\
\hline Yes & $10(58.8)$ & $7(41.2)$ & & 0 & $17(100)$ & \\
\hline \multicolumn{7}{|c|}{ Amputation } \\
\hline No & 196(32.9) & $399(67.1)$ & 0.118 & $274(45.1)$ & $32 I(53.9)$ & 0.533 \\
\hline Yes & 0 & $5(100)$ & & $3(60.0)$ & $2(40.0)$ & \\
\hline Total & $196(32.7)$ & $404(67.3)$ & & $277(46.2)$ & $323(53.8)$ & \\
\hline
\end{tabular}

Based on this research, age, DM, hypertension, obesity, abdominal obesity, and history of stroke were significantly associated with the hypertension and DM. These determinants are highly associated with patients' lifestyles and are known risk factors for development of diabetic and hypertensive complications, and they can put patients at further risk of CVD complications.

This research also showed that age, smoking, hypertension, and monthly income had significant associations with higher CVR. Another study showed similar results: age, blood-glucose concentration, presence of hypertension, and smoking were major predictors of macrovascular disease in patients with DM. ${ }^{18}$ Another study also showed similar results: age, sex, blood pressure, total cholesterol, smoking, DM, family history of CVD, sedentary lifestyle, and obesity were the main determinants of CVR. ${ }^{19}$ Also, poor glycemic control, obesity, dyslipidemia, and hypertension are classical risk factors for the development of CVD in subjects with DM. ${ }^{4}$ Current research data indicate that metabolic syndrome, insulin resistance, lipid profile, and DM are strongly linked with CVD. ${ }^{20}$ Institutionalizing controlling modalities for these risk factors that can predispose these patients to further CVR is essential.

Age, hypertension, and abdominal obesity showed significant association with glycemic control in patients with DM. Though age cannot be modified, hypertension and obesity must be adjusted to control DM and prevent the CVD complications. Although smoking, BMI, and abdominal obesity did not show significant associations with blood-pressure control, they were significantly associated with hypertension and $\mathrm{DM}$, and thus they can indirectly predispose patients to further hypertensive and CVD complications.

We identified that $10.8 \%$ of patients were obese and that obesity was associated with hypertension, DM, and glycemic control. This result was lower than other research in which $18.2 \%$ were obese. ${ }^{16}$ Although the prevalence of obesity in these patients was low, it is crucial to introduce mechanisms to monitor and regulate the BMI of patients, which can further predispose them to different CVR. 
Table 4 Association of patients' background with cardiovascular risk $(n=600)$

\begin{tabular}{|c|c|c|c|c|c|}
\hline & & & & & Ip \\
\hline & \multicolumn{2}{|c|}{$>10 \%$ risk } & \multicolumn{2}{|c|}{$<10 \%$ risk } & \\
\hline & $\mathbf{n}$ & $\%$ & $\mathbf{n}$ & $\%$ & \\
\hline \multicolumn{6}{|l|}{ Age (years) } \\
\hline$<21$ & 0 & & 6 & 100 & $<0.001$ \\
\hline $21-40$ & 2 & 3.9 & 49 & 96.1 & \\
\hline $4 I-60$ & 5 & 1.6 & 311 & 98.4 & \\
\hline$\geq 61$ & 32 & 14.1 & 195 & 85.9 & \\
\hline \multicolumn{6}{|l|}{ Sex } \\
\hline Female & 9 & 3.7 & 234 & 96.3 & 0.022 \\
\hline Male & 30 & 8.4 & 327 & 91.6 & \\
\hline \multicolumn{6}{|l|}{ Subzone } \\
\hline Massawa & 39 & 6.6 & 549 & 93.4 & 0.974 \\
\hline Foro & 0 & 0 & 5 & 100 & \\
\hline Shieb & 0 & 0 & 4 & 100 & \\
\hline Others & 0 & 0 & 3 & 100 & \\
\hline \multicolumn{6}{|l|}{ Ethnicity } \\
\hline Afar & 2 & 5.1 & 37 & 94.9 & 0.861 \\
\hline Tigrigna & 21 & 6.0 & 331 & 94.0 & \\
\hline Saho & 4 & 10.5 & 34 & 89.5 & \\
\hline Tigre & 11 & 6.9 & 149 & 93.1 & \\
\hline Other & I & 9.1 & 10 & 90.9 & \\
\hline \multicolumn{6}{|l|}{ Smoking } \\
\hline No & 29 & 5.3 & 523 & 94.7 & $<0.001$ \\
\hline Yes & 10 & 20.8 & 38 & 79.2 & \\
\hline \multicolumn{6}{|c|}{ Alcohol intake } \\
\hline No & 33 & 6.1 & 511 & 93.9 & 0.179 \\
\hline Yes & 6 & 10.7 & 50 & 89.3 & \\
\hline \multicolumn{6}{|l|}{ DM } \\
\hline No & 11 & 5.7 & 183 & 94.3 & 0.569 \\
\hline Yes & 28 & 6.9 & 378 & 93.1 & \\
\hline \multicolumn{6}{|c|}{ Hypertension } \\
\hline No & 9 & 3.4 & 254 & 96.6 & 0.007 \\
\hline Yes & 30 & 8.9 & 307 & 91.1 & \\
\hline \multicolumn{6}{|l|}{ BMI } \\
\hline$<18 \mathrm{~kg} / \mathrm{m}^{2}$ & 5 & 10.0 & 45 & 90.0 & 0.317 \\
\hline $18-25 \mathrm{~kg} / \mathrm{m}^{2}$ & 26 & 7.4 & 327 & 92.6 & \\
\hline $26-30 \mathrm{~kg} / \mathrm{m}^{2}$ & 6 & 4.5 & 125 & 95.5 & \\
\hline$>30 \mathrm{~kg} / \mathrm{m}^{2}$ & 2 & 3.1 & 63 & 96.9 & \\
\hline
\end{tabular}

(Continued)
Table 4 (Continued).

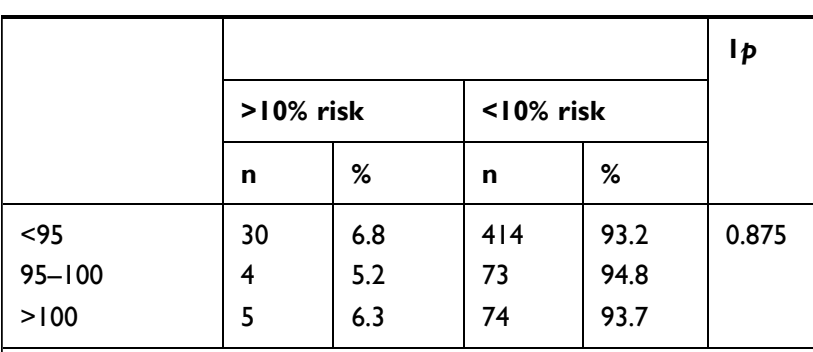

Monthly income (ERN)

\begin{tabular}{|l|l|l|l|l|l|}
\hline$<500$ & 13 & 5.9 & 207 & 94.1 & 0.007 \\
$500-1,000$ & 10 & 9.6 & 94 & 90.4 & \\
$\mathrm{I}, 00 \mathrm{I}-2,000$ & 5 & 2.6 & 185 & 97.4 & \\
$>2,000$ & $1 \mathrm{I}$ & 12.8 & 75 & 87.2 & \\
\hline
\end{tabular}

Distance from home to work

\begin{tabular}{|l|l|l|l|l|l|}
\hline$<1 \mathrm{~km}$ & 18 & 6.0 & 284 & 94.0 & 0.636 \\
$\mathrm{I}-5 \mathrm{~km}$ & 20 & 7.4 & 250 & 92.6 & \\
$>5 \mathrm{~km}$ & $\mathrm{I}$ & 3.6 & 27 & 96.4 & \\
\hline \multicolumn{5}{|l|}{ Vision problem } \\
\hline \begin{tabular}{l|l|l|l|l|} 
No \\
Yes
\end{tabular} & 24 & 5.3 & 428 & 94.7 & 0.039 \\
\hline
\end{tabular}

History of stroke

\begin{tabular}{|l|l|l|l|l|l|}
\hline No & 37 & 6.3 & 546 & 93.7 & 0.372 \\
Yes & 2 & 11.8 & 15 & 88.2 & \\
\hline
\end{tabular}

History of amputation

\begin{tabular}{|l|l|l|l|l|l|}
\hline $\begin{array}{l}\text { No } \\
\text { Yes }\end{array}$ & $\begin{array}{l}39 \\
0\end{array}$ & 6.6 & $\begin{array}{l}556 \\
5\end{array}$ & $\begin{array}{l}93.4 \\
100\end{array}$ & 0.554 \\
\hline Total & 39 & 6.5 & 561 & 93.5 & \\
\hline
\end{tabular}

The Saho had poorly controlled hypertension and DM compared to the other ethnic groups. This could be due to the fact that they have less knowledge and lower living standards than other ethnic groups and they may not appropriately apply the strategies used to control these chronic diseases.

Overall, $8 \%$ patients with DM and hypertension were smokers, and smoking had a significant association with higher CVR. Advocating cessation of smoking in general and in these patients in particular is very advisable to prevent chronic complications of these diseases. Two-thirds of patients with DM and hypertension had well-controlled FBS and blood pressure, respectively. This result further led to most of these patients having a CVR of $<10 \%$ in the coming 10 years. However, as these two chronic diseases are 
Table 5 Association of patients' medical profiles with mean FBS and mean blood-pressure levels of patients $(n=600)$

\begin{tabular}{|c|c|c|c|c|c|c|}
\hline & \multicolumn{2}{|c|}{ Mean FBS (mg/dL) } & \multirow[t]{3}{*}{$p$} & \multicolumn{2}{|c|}{ Mean BP $(\mathrm{mmHg})$} & \multirow[t]{3}{*}{$p$} \\
\hline & $>150$ & $75-150$ & & $<130 / 80$ & $>130 / 80$ & \\
\hline & n (\%) & n (\%) & & n (\%) & n (\%) & \\
\hline \multicolumn{7}{|c|}{ Age (years) } \\
\hline$<21$ & $4(66.7)$ & $2(33.3)$ & $<0.001$ & $6(100)$ & 0 & 0.003 \\
\hline $21-40$ & $23(60.5)$ & $15(39.5)$ & & $43(84.3)$ & $8(15.7)$ & \\
\hline $4 I-60$ & $98(42.2)$ & I34(58.8) & & $259(82.0)$ & $57(18.0)$ & \\
\hline$\geq 61$ & $43(33.6)$ & $85(66.4)$ & & $159(70.0)$ & $68(30.0)$ & \\
\hline \multicolumn{7}{|c|}{ Subzone } \\
\hline Massawa & $163(41.4)$ & $231(58.6)$ & 0.273 & $457(77.7)$ & $|3|(22.3)$ & 0.971 \\
\hline Foro & $3(100)$ & 0 & & $4(80.0)$ & $I(20.0)$ & \\
\hline Others & 0 & $3(100)$ & & $3((75.0)$ & $\mathrm{I}(25.0)$ & \\
\hline Shieb & $\mathrm{I}(25.0)$ & $3(75.0)$ & & $3(100)$ & 0 & \\
\hline \multicolumn{7}{|c|}{ Ethnicity } \\
\hline Afar & $8(38.1)$ & $13(61.9)$ & 0.651 & $32(82.1)$ & $7(17.9)$ & 0.933 \\
\hline Tigrigna & $100(41.7)$ & $140(58.3)$ & & $270(76.7)$ & $82(23.3)$ & \\
\hline Saho & $12(46.2)$ & $14(53.8)$ & & $30(78.9)$ & $8(21.1)$ & \\
\hline Tigre & $44(4 I . I)$ & $63(58.9)$ & & $125(78.1)$ & $35(21.9)$ & \\
\hline Other & $4(40.0)$ & $6(60.0)$ & & $10(90.9)$ & $\mathrm{I}(9.1)$ & \\
\hline \multicolumn{7}{|c|}{ Smoking history } \\
\hline No & $156(42.1)$ & $215(57.9)$ & 0.795 & $426(77.2)$ & $126(22.8)$ & 0.187 \\
\hline Yes & $12(36.4)$ & $21(63.6)$ & & $4 I(85.4)$ & $7(14.6)$ & \\
\hline \multicolumn{7}{|c|}{ Alcohol-intake history } \\
\hline No & $145(40.5)$ & $213(59.5)$ & 0.048 & $423(77.8)$ & $|2|(22.2)$ & 0.889 \\
\hline Yes & $22(48.9)$ & $23(5 I .1)$ & & $44(78.6)$ & $12(2 \mid .4)$ & \\
\hline \multicolumn{7}{|l|}{ DM } \\
\hline No & 0 & $6(3.1)$ & $<0.001$ & $130(67.0)$ & $64(33.0)$ & $<0.001$ \\
\hline Yes & $168(4 \mid .4)$ & $230(56.7)$ & & $337(83.0)$ & $69(17.0)$ & \\
\hline \multicolumn{7}{|c|}{ Hypertension } \\
\hline No & $127(48.3)$ & $136(5 \mid .7)$ & $<0.001$ & $236(89.7)$ & $27(10.3)$ & $<0.001$ \\
\hline Yes & $4 I(10.1)$ & $100(89.9)$ & & $23 I(68.5)$ & 106(31.5) & \\
\hline \multicolumn{7}{|c|}{ BMI $\left(\mathbf{k g} / \mathbf{m}^{2}\right)$} \\
\hline$<18$ & II (40.7) & $16(59.3)$ & 0.021 & $4 I(82.0)$ & $9(18.0)$ & 0.765 \\
\hline $18-25$ & $98(43.4)$ & $128(56.7)$ & & $276(78.2)$ & $77(21.8)$ & \\
\hline $26-30$ & $38(38.4)$ & $61(61.6)$ & & $102(77.3)$ & $30(22.7)$ & \\
\hline$>30$ & $21(40.3)$ & $3 I(59.7)$ & & $48(73.8)$ & $17(26.2)$ & \\
\hline \multicolumn{7}{|c|}{ Abdominal circumference $(\mathrm{cm})$} \\
\hline$<95$ & $125(45.1)$ & $152(54.9)$ & $<0.001$ & $35 I(79.1)$ & $93(20.9)$ & 0.090 \\
\hline $95-100$ & $18(27.3)$ & $48(72.7)$ & & $62(80.5)$ & $15(19.5)$ & \\
\hline$>100$ & $24(40.0)$ & $36(60.0)$ & & $54(68.4)$ & $25(31.6)$ & \\
\hline
\end{tabular}


Table 5 (Continued).

\begin{tabular}{|c|c|c|c|c|c|c|}
\hline & \multicolumn{2}{|c|}{ Mean FBS (mg/dL) } & \multirow[t]{3}{*}{$p$} & \multicolumn{2}{|c|}{ Mean BP $(\mathbf{m m H g})$} & \multirow[t]{3}{*}{$p$} \\
\hline & $>150$ & $75-150$ & & $<130 / 80$ & $>130 / 80$ & \\
\hline & n (\%) & n (\%) & & n (\%) & n (\%) & \\
\hline$<500$ & $65(43.9)$ & $83(56.1)$ & 0.017 & $169(76.8)$ & $5 I(23.2)$ & 0.966 \\
\hline $500-1,000$ & $23(40.4)$ & $34(59.6)$ & & $82(78.8)$ & $22(21.2)$ & \\
\hline $1,001-2,000$ & $60(44.8)$ & $74(55.2)$ & & $148(77.9)$ & $42(22.1)$ & \\
\hline$>2,000$ & $20(30.8)$ & $45(69.2)$ & & $68(79.1)$ & 18(20.9) & \\
\hline \multicolumn{7}{|c|}{ Distance from home to work $(\mathrm{km})$} \\
\hline$<1$ & $94(81.0)$ & $116(19.0)$ & 0.150 & $228(75.5)$ & $74(24.5)$ & 0.300 \\
\hline $1-5$ & $7 I(40.3)$ & $105(59.7)$ & & $218(80.7)$ & $52(19.3)$ & \\
\hline$>5$ & $3(16.7)$ & $15(83.3)$ & & $21(75.0)$ & $7(25.0)$ & \\
\hline \multicolumn{7}{|c|}{ Vision problem } \\
\hline No & $124(40.9)$ & $179(59.1)$ & 0.864 & $355(78.5)$ & $97(21.5)$ & 0.467 \\
\hline Yes & $44(43.6)$ & $57(56.4)$ & & $\mathrm{II} 2(75.7)$ & $36(24.3)$ & \\
\hline \multicolumn{7}{|c|}{ History of stroke } \\
\hline No & $165(41.6)$ & $232(58.4)$ & 0.066 & $454(77.9)$ & $129(22.1)$ & 0.891 \\
\hline Yes & $3(42.9)$ & $4(57.1)$ & & $13(76.5)$ & $4(23.5)$ & \\
\hline \multicolumn{7}{|c|}{ Amputation history } \\
\hline No & $166(41.6)$ & $233(58.4)$ & 0.293 & $463(77.8)$ & $132(22.2)$ & 0.907 \\
\hline Yes & $2(40.0)$ & $3(60.0)$ & & $4(80.0)$ & $I(20.0)$ & \\
\hline Total & I68(4I.6) & $236(58.4)$ & & $467(77.8)$ & $133(22.2)$ & \\
\hline
\end{tabular}

significant causes of CVD and lead to chronic complications, regulating and controlling of them are fundamental.

When DM exists in patients with established CVD, absolute risk of future events is very high. ${ }^{9}$ Based on selfreported responses of the patients, some had already developed complications of cerebrovascular accidents and amputation, and those with a history of stroke and vision problems had higher CVR and showed a significant association with hypertension compared to their counterparts. Furthermore, all patients who had already developed cerebrovascular accidents were hypertensive. Therefore, they were at very high risk, and strict control of hypertension would further prevent repeated CV events.

A third of the patients had self-reported vision problems. Though the causes of the vision problems could not be identified from their reports, this could be associated with chronic complications of DM and hypertension, pointing to the need for urgent ophthalmic screening to identify higher prevalence of vision problems and ophthalmic complications of hypertension and DM.
As hypertension was strongly associated with glycemic control and CVR, proper management of blood pressure will further prevent CVD complications on these patients. In addition, controlling modifiable factors, such as smoking and strict control of DM and hypertension, could markedly decrease CVR in patients with DM and hypertension.

Though different guidelines have mentioned that routine assessment of microalbuminuria, resting electrocardiography, transthoracic echocardiography, coronary artery-calcium score, ankle-brachial index, and novel cardiac biomarkers are indicated in patients with DM and hypertension or if CVD is suspected, ${ }^{10}$ most of these parameters were not available in our setting. Therefore, we were not able to investigate patients with these investigation modalities and use in our study.

Researches has found that there are several CVR factors, such as old age, male sex, hypertension, DM, dyslipidemia, smoking, sedentary lifestyle, and familial history of CVD. ${ }^{20}$ The prevalence of smoking, obesity, and 
abdominal obesity were low in these patients in our setting. Age, smoking, hypertension, and monthly income were associated with higher CVR, and all the general risk factors were associated with hypertension and DM of patients, predisposing them to further CVD risks. Further research is needed to determine the prevalence and association of these risk factors in our setting.

Many exposure scenarios have been strongly associated with epigenetic changes, ultimately promoting the development of proatherosclerotic profiles. ${ }^{21}$ Accumulating evidence suggests that pollutants and climate changes generate a kaleidoscope of adverse effects on human health, including cardiac biology, and especially in vulnerable subjects, such as those with an inherited proatherosclerotic milieu. $^{22}$ In our setting, there were no identifiable local risk factors of CVD or DM. Though research has not been done on this issue, the local diet of this community consists mostly of carbohydrates and vegetables, and the prevalence of obesity seems low in our setting. Rampant local therapy and exposure to pollutants that can predispose people to CVR are not common in our community.

\section{Conclusion}

DM was associated with BMI and abdominal obesity of $>30 \mathrm{~kg} / \mathrm{m}^{2}$ and $>100 \mathrm{~cm}$, respectively. Age was strongly associated with DM, hypertension, CVD, glycemic control, and mean blood pressure. DM, hypertension, BMI, abdominal obesity, and history of stroke had significant associations with history of hypertension and DM. Smoking, hypertension and monthly income had significant associations with higher CVR in the coming 10 years. Hypertension and abdominal obesity showed significant associations with glycemic control, and mean blood pressure was significantly associated with DM and hypertension.

\section{Recommendations}

Assessment of CVD risk is of great importance for preventing adverse $\mathrm{CV}$ outcomes, and can be a useful tool for prevention of poor treatment of individuals at high risk, as well as inappropriate treatment of subjects at low risk in this population. Modifiable factors that show increased risk of $\mathrm{CV}$ events in the coming 10 years should be analyzed and appropriate measures taken to reduce them. Smoking cessation should be advised, and strict control of hypertension is vital to decrease the CVD incidence in these patients with high CVR. Regular exercise and a balanced and controlled diet are two of the best strategies, as BMI and abdominal obesity were associated with higher CVR and poorly controlled DM.

The National Diabetes Association and policy-makers should incorporate and advocate for the introduction of CVR-prediction strategies in national guidelines for these diseases. Health professionals should consider and regularly use CVR-prediction charts during management and followup of these patients, and this should be individualized for every patient with DM and hypertension to decrease CVR. Policy-makers should also allocate appropriate resources and develop services that can maximize health in patients with DM and hypertension, who are at high CVR.

\section{Abbreviations}

WHO, World Health Organization; CVR, cardiovascular risk; CVD, cardiovascular disease; BMI, body mass index; DM, diabetes mellitus; FBS, fasting blood sugar; NCD, Non-communicable disease.

\section{Acknowledgments}

The authors acknowledge the patients and Massawa Hospital's non-communicable-disease clinic staff for their participation in data collection.

\section{Funding}

This research had no source of funding.

\section{Disclosure}

The authors report no conflicts of interest for this work.

\section{References}

1. Organization WH. Diabetes. Fact Sheet N312 2014. http://www.who. int $/$ mediacentre/factsheets/fs $312 / \mathrm{en} / \% 5 \mathrm{D}$.

2. Bertoluci MC. Cardiovascular risk assessment in patients with diabetes. Diabetol Metab Syndrv. 2017;9:PMC5397821. doi:10.1186/ s13098-017-0225-1

3. Yuk E, Wan F, Ten-year risk prediction models of complications and mortality of Chinese patients with diabetes mellitus in primary care in Hong Kong. doi:10.1136/bmjopen-2018-023070.

4. de MattosMatheus AS. Impact of diabetes on cardiovascular disease. Int J Hypertens. 2013;2013:Article ID 653789. doi:10.1155/2013/ 653789

5. Kalofoutis C. Type II diabetes mellitus and cardiovascular risk factors: current therapeutic approaches. Exp Clin Cardiol. 2007;12(1):17-28.

6. Scott M, Benjamin G. Diabetes and cardiovascular disease. Circulation. 1999;100:1134-1146. doi:10.1161/01.CIR.100.10.1134

7. Grundy SM. Diabetes and Cardiovascular Disease Executive Summary Conference Proceeding for Healthcare Professionals From a Special Writing Group of the American Heart Association. Circulation. 2002;105:2231-2239. doi:10.1161/01.CIR.0000013952.86046.DD 
8. Pintóa X, Corbell E. Factors Predictive of Cardiovascular Disease in Patients with Type-2 Diabetes and Hypercholesterolemia. ESODIAH Study. 2007;60(3):251-258. doi:10.1016/S1885-5857(07)60149-2

9. Buse JB. Primary prevention of cardiovascular diseases in people with diabetes mellitus. Diabetes Care. 2007;30(1):162-172. doi: $10.2337 / \mathrm{dc} 07-9917$

10. Cosentino F, Grant PJ, Aboyans V, Bailey CJ, Ceriello A, Delgado V. 2019 ESC Guidelines on diabetes, pre-diabetes, and cardiovascular diseases developed in collaboration with the EASD: the Task Force for diabetes, pre-diabetes, and cardiovascular diseases of the European Society of Cardiology (ESC) and the European Association for the Study of Diabetes (EASD). Eur Heart $J$. 2020;41(2):255-323. doi:10.1093/eurheartj/ehz486

11. Mufunda J, Nyarango P, Kosia A, et al. Noncommunicable diseases in Africa: a silent hypertension epidemic in Eritrea. $J$ Hum Hypertens. 2005;19(3):255-256. doi:10.1038/sj.jhh.1001802

12. Usman A, Mebrahtu G, Mufunda J, et al. Prevalence of non-communicable disease risk factors in Eritrea. Ethn Dis. 2006;16(2):542-546.

13. Adgoy ET, et al. Diabetic complications among adult diabetic patients; Halibet regional referral hospital ZobaMaekel, Asmara, Eritrea. Int J Med Health Prof Res. 2016;3(2):82-91.

14. Ministry of Health; Eritrea M. National STEPS Survey for Chronic Non Communicable Diseases and Their Risk Factors. DPC/NCD, Ed.;2012.

15. Ministry of Health. Northern Red Sea Branch. Eritrea:: Massawa Hospital Annual report; 2020.
16. Herath $\mathrm{H}$, Weerarathna T, Umesha D. Cardiovascular risk assessment in type 2 diabetes mellitus: comparison of the World Health Organization/International Society of Hypertension risk prediction charts versus UK Prospective Diabetes Study risk engine. Vasc Health Risk Manag. 2015;11:583-589. doi:10.2147/VHRM.S90126

17. Paula EA, De paula R, da Costa DMN. Cardiovascular risk assessment in hypertensive patients. Rev Latino-Am Enfermagem. 2013;21 (3):820-827. doi:10.1590/S0104-11692013000300023

18. Zamoraa A, Marrugat J. Prognosis of diabetic patients with coronary heart disease. Revista Española De Cardiología. 2002;55 (7):751-762.

19. ŞükrüUlusoy. Assessment of cardiovascular risk in hypertensive patients: a comparison of commonly used risk scoring programs. Kidney Int Suppl. 2011;3(4):340-342. doi:10.1038/kisup.2013.72.

20. Vesa CM, Popa L, Popa AR. Current data regarding the relationship between Type 2 diabetes mellitus and cardiovascular risk factors. Diagnostics. 2020;10(5):314. doi:10.3390/diagnostics10050314

21. Baccarelli A, Ghosh S. Environmental exposures, epigenetics and cardiovascular disease. Curr Opin Clin Nutr Metab Care. 2012;15:323-329. doi:10.1097/MCO.0b013e328354bf5c

22. De Blois J, Kjellstrom T, Agewall S, et al. The Effects of Climate Change on Cardiac Health. Cardiology. 2015;131:209-217. doi:10.1159/000398787

Diabetes, Metabolic Syndrome and Obesity: Targets and Therapy

\section{Publish your work in this journal}

Diabetes, Metabolic Syndrome and Obesity: Targets and Therapy is an international, peer-reviewed open-access journal committed to the rapid publication of the latest laboratory and clinical findings in the fields of diabetes, metabolic syndrome and obesity research. Original research, review, case reports, hypothesis formation, expert opinion and commentaries are all considered for publication. The manuscript management system is completely online and includes a very quick and fair peer-review system, which is all easy to use. Visit http://www.dovepress.com/testimonials.php to read real quotes from published authors.

Submit your manuscript here: https://www.dovepress.com/diabetes-metabolic-syndrome-and-obesity-targets-and-therapy-journal 